\title{
Thermodynamic properties of polymer solutions: effect of free volume fraction of solvent molecules
}

\author{
Jyh-Ping Hsu*, Sung-Hwa Lin \\ Department of Chemical Engineering, National Taiwan University, Taipei 10617, Taiwan, ROC \\ Received 18 April 2003; received in revised form 3 October 2003; accepted 3 October 2003
}

\begin{abstract}
Knowledge about the thermodynamic properties of a polymer solution is essential to its applications. These properties are derived on the basis of a statistical mechanics approach by modifying the classic Flory-Huggins theory in this study. The analytical result derived is fitted to the available experimental data such as toluene-polystyrene and benzene-silicone polymer solutions in the literature, and its performance is satisfactory. We show that the inconsistency between the Flory-Huggins theory and experimental observations for many polymer solutions might arise from the negligence of the effects of the free volume fractions of solvent and polymer and the change in the disorientation entropy of polymer molecules.
\end{abstract}

(C) 2003 Elsevier Ltd. All rights reserved.

Keywords: Polymer solutions; Thermodynamic properties; Modified Flory-Huggins theory

\section{Introduction}

Knowledge about the behaviors or the thermodynamics properties of a polymer solution is essential to its processing. Reliable analytical expressions which are capable of predicting these information are both desirable and imminent for applications in modern high technologies such as photoresist engineering [1-3], plastic optical fiber fabrication [4-6], and imaging focus elements [7-10], to name a few. Among various available results for a polymer solution, the well known Flory-Huggins theory [11]

$$
\begin{aligned}
\mu_{\mathrm{s}} & -\mu_{\mathrm{s}}^{0} \\
& =R T\left[\ln \phi_{\mathrm{s}}+\left(1-\frac{1}{z_{\mathrm{p}}}\right)\left(1-\phi_{\mathrm{s}}\right)+\chi\left(1-\phi_{\mathrm{s}}\right)^{2}\right]
\end{aligned}
$$

is widely adopted, where $\mu_{\mathrm{s}}$ and $\mu_{\mathrm{s}}^{0}$ are, respectively, the chemical potential of solvent in polymer solution and that at its pure state, $\phi_{\mathrm{s}}$ is the volume fraction of solvent, $z_{\mathrm{p}}$ is the ratio of the volume of each polymer molecule to that of solvent molecule, and $\chi$ is the Flory-Huggins parameter or the susceptibility, which is responsible for the difference of

\footnotetext{
* Corresponding author. Tel.: +886-2-23637448; fax: +886-223623040.

E-mail address: jphsu@ccms.ntu.edu.tw (J.P. Hsu).
}

intermolecular forces between pure state and mixture. Parameters $z_{\mathrm{p}}$ and $\chi$ can be derived by

$$
\begin{aligned}
& z_{\mathrm{p}}=\frac{M_{\mathrm{p}} / \rho_{\mathrm{p}}}{M_{\mathrm{s}} / \rho_{\mathrm{s}}} \\
& \chi=\frac{Z\left[\varepsilon_{\mathrm{su}}-\left(\varepsilon_{\mathrm{ss}}+\varepsilon_{\mathrm{uu}}\right) / 2\right]}{k T}
\end{aligned}
$$

In these expressions $M_{\mathrm{p}}$ and $M_{\mathrm{s}}$ are, respectively, the molecular weights of polymer and solvent, $\rho_{\mathrm{p}}$ and $\rho_{\mathrm{s}}$ are, respectively, the densities of polymer and solvent, $Z$ is the coordination number of each polymer unit and solvent molecule, $k$ and $T$ are, respectively, the Boltzmann constant and the absolute temperature, and $\varepsilon_{\mathrm{su}}, \varepsilon_{\mathrm{ss}}$ and $\varepsilon_{\mathrm{uu}}$ are the intermolecular potential energy of solvent molecule-polymer unit pair, solvent molecule-solvent molecule pair and polymer unit-polymer unit pair, respectively. Here, a polymer unit is defined as the part of polymer of which volume is equal to that of solvent molecule, and is different in usual from the monomer of polymer. The coordination number of each polymer unit and solvent molecule is taken as the number of the nearest polymer units and solvent molecules' surrounding them, and it is assumed to be constant throughout the solution. Flory [11] suggests that $\chi$ ranges from 0.3 to 0.8 .

The Flory-Huggins theory expressed in Eq. (1) is based 
on the permutation calculation of polymer molecules arrangement in an artificial lattice model. According to the assumption made by them, $\chi$ is a weak function of polymer concentration by its definition as Eq. (1b). However, for most of polymer solution, the value of $\chi$ is found to vary a lot with the content of solvent added, except for a few polymer solutions, e.g. the rubberbenzene system [12,13]. Some modification in permutation are proposed [14-18], for example the Miller's result [16]:

$$
\begin{aligned}
\mu_{\mathrm{s}}- & \mu_{\mathrm{s}}^{0} \\
= & R T\left\{\ln \phi_{\mathrm{s}}-\left(1-\frac{1}{z_{\mathrm{p}}}\right) \frac{Z}{2} \ln \left[1-\frac{2\left(1-\phi_{\mathrm{s}}\right)}{Z}\right]\right. \\
& \left.+\chi\left(1-\phi_{\mathrm{s}}\right)^{2}\right\}
\end{aligned}
$$

Unfortunately, the improvement made by these works is found to be limited, and in which the estimated values of $Z$ are unrealistic in usual $[19,20]$.

The enthalpy change of a polymer solution on mixing is usually estimated by calorimetric measurements. Experimental evidence reveals that the absolute value of $\chi$ deduced directly from the mixing heat is much smaller than that obtained directly from Eq. (1), and it is insensitive to the variation of the concentration of polymer solution [21]. This implies that in Flory-Huggins' theory, the expression for the entropy change on mixing is inadequate. Several attempts were made to correct the contribution of the entropy part of the free energy change on mixing. For example, the UNIFAC method, which is a semi-empirical theory for the estimation of the activity coefficient based on a group contribution method, was widely used [22,23]. A rule common to previous works is the additive property of entropy change contributed by combinatorial, $\Delta S_{\mathrm{c}}$, and the contribution arising from the changes in both the interaction force and the free volume, $\Delta S_{\mathrm{r}}$, the residual contribution. We have

$\Delta S_{\text {mix }}=\Delta S_{\mathrm{c}}+\Delta S_{\mathrm{r}}$

where $\Delta S_{\text {mix }}$ is the total entropy change on mixing. The combinatorial part, $\Delta S_{\mathrm{c}}$, is responsible for both the effect of the sizes of molecules and that of their shape, and can be described satisfactorily by Flory-Huggins' theory. In general, the contribution of the change in free volume to $\Delta S_{\mathrm{r}}$ is more significant than that of the change in the interaction force. An important correction for the contribution of the change of free volume to the entropy change on mixing was proposed by Elbro et al. [24]. Based on the result of Hildebrand [25] for a regular binary system, they suggested that the effect of the difference in the free volume of polymer and that of solvent on the entropy change on mixing for a polymer solution should be considered. The analytical expression derived by Elbro et al. [24] for the entropy change of a polymer solution was widely adopted in relevant studies [26,27]. The free volume adopted by Elbro et al., however, is inappropriate because it was overestimated. In this study, the entropy change of a polymer solution is derived based on a statistical mechanics approach taking the size distribution of polymer molecules into account. The applicability of the result derived is justified by examining the available experimental data in the literature.

\section{Model}

Kirkwood [28] proposed the following configuration partition function for a solvent having $N_{\mathrm{s}}$ indistinguishable molecules:

$$
\begin{aligned}
Q_{\mathrm{s}} & =\frac{\sigma_{\mathrm{s}}^{N_{\mathrm{s}}}}{N_{\mathrm{s}} !} \int_{V_{\mathrm{s}}} \cdots \int_{V_{\mathrm{s}}} \mathrm{e}^{-U\left(\underline{r}_{1}, \cdots, \underline{r}_{N_{\mathrm{s}}}\right) / k T} \mathrm{~d} \underline{r}_{1} \cdots \mathrm{d} \underline{r}_{N_{\mathrm{s}}} \\
& \cong \frac{1}{N_{\mathrm{s}} !} \exp \left(\frac{-N_{\mathrm{s}} Z \varepsilon_{\mathrm{ss}}}{2 k T}\right)\left(\sigma_{\mathrm{s}} N_{\mathrm{s}} v_{\mathrm{f}, \mathrm{s}}^{0}\right)^{N_{\mathrm{s}}}
\end{aligned}
$$

where $\sigma_{\mathrm{s}}$ is a correction factor for solvent, $V_{\mathrm{s}}$ and $\underline{r}_{i}$ are, respectively, the total volume of solvent and the position vector of molecule $i, U$ is the total potential energy of solvent, which depends only on the positions of molecules, $\underline{r}_{i}, i=1,2, \cdots, N_{\mathrm{s}}$, and $v_{\mathrm{f}, \mathrm{s}}^{0}$ is the mean free volume of solvent, i.e. the total free volume of solvent divided by $N_{\mathrm{s}}$. $\sigma_{\mathrm{s}}$ has the meaning of the extent of sharing the free volume between molecules, and it ranges from 1 for perfect gas to (1/e) for perfect crystal solid. Eq. (4a) can be interpreted as that each solvent molecule moves through a free volume $\sigma_{\mathrm{s}} N_{\mathrm{s}} v_{\mathrm{f}, \mathrm{s}}^{0}$ in an average potential field of strength $Z \varepsilon_{\mathrm{ss}}$. The potential field arises mainly from the presence of the nearest molecules. The contribution by other molecules to this field is taken into account by considering the coordination number. For that reason, the coordination number $Z$ should be interpreted as an effective, but not exact, coordination number. Following the ideal of Kirkwood, the configuration partition function of $N_{\mathrm{p}}$ different-sized, distinguishable polymer molecules can be expressed as

$Q_{\mathrm{p}} \cong \exp \left[-\frac{(Z-2) \varepsilon_{\mathrm{uu}}}{2 k T} \sum_{i=1}^{N_{\mathrm{p}}} z_{\mathrm{p} i}\right]\left(\sigma_{\mathrm{p}} v_{\mathrm{f}, \mathrm{u}}^{0} \sum_{i=1}^{N_{\mathrm{p}}} z_{\mathrm{p} i}\right)^{N_{\mathrm{p}}}$

where $z_{\mathrm{p} i}$ is the volume ratio of $i$ polymer molecule to solvent molecule, $\sigma_{\mathrm{p}}$ is the correction factor for polymer, and $v_{\mathrm{f}, \mathrm{u}}^{0}$ is the mean free volume of polymer unit, i.e. the total free volume of polymer divided by $\sum_{i=1}^{N_{\mathrm{p}}} z_{\mathrm{p} i}$. Because except at an extremely high temperature, both $\sigma_{\mathrm{s}}$ and $\sigma_{\mathrm{p}}$ remain roughly constant [29], and the effect arising from the non-random mixing is scarcely significant $[17,18]$, the configuration partition function for mixing $N_{\mathrm{s}}$ solvent molecules with $N_{\mathrm{p}}$ 
different-sized polymer molecules under zero excess volume is with $\bar{M}_{\mathrm{n}}$ being the number-averaged molecular weight of polymer molecules. According to the definition of volume

$$
\begin{aligned}
Q_{\mathrm{ps}} \cong & \frac{\sigma_{\mathrm{s}}^{N_{\mathrm{s}}} \sigma_{\mathrm{p}}^{N_{\mathrm{p}}}}{N_{\mathrm{s}} !} \exp \left\{-\frac{N_{\mathrm{s}} Z\left[\phi_{\mathrm{s}} \varepsilon_{\mathrm{ss}}+\left(1-\phi_{\mathrm{s}}\right) \varepsilon_{\mathrm{su}}\right]+(Z-2)\left[\phi_{\mathrm{s}} \varepsilon_{\mathrm{su}}+\left(1-\phi_{\mathrm{s}}\right) \varepsilon_{\mathrm{uu}}\right] \sum_{i=1}^{N_{\mathrm{p}}} z_{\mathrm{p} i}}{2 k T}\right\} \\
& \times\left(N_{\mathrm{s}} v_{\mathrm{f}, \mathrm{s}}+v_{\mathrm{f}, \mathrm{u}} \sum_{i=1}^{N_{\mathrm{p}}} z_{\mathrm{p} i}\right)^{N_{\mathrm{s}}+N_{\mathrm{p}}}
\end{aligned}
$$

where $v_{\mathrm{f}, \mathrm{s}}$ and $v_{\mathrm{f}, \mathrm{u}}$ are, respectively, the contributions to the free volume from each solvent molecule and each polymer unit, and depending upon the magnitude of the intermolecular force between solvent molecule and polymer unit, these parameters may vary slightly on mixing. Eq. (5) is an extension of the configuration partition function for small molecule liquid mixtures [29], and it implies that the free volume is of additive nature. The numerator of the exponential term on the right-hand side of Eq. (5) suggests that the possibility of finding a solvent molecule or polymer unit near a specified solvent molecule or polymer unit is proportional to their volume fractions in a polymer solution. Suppose that the internal partition functions of solvent and polymer, including the disorientation (or rearrangement) partition function of polymer molecules, are not altered on mixing. Then based on statistical thermodynamics the change of entropy on mixing can be expressed as

$\Delta S_{\text {mix }}=k \ln \left(\frac{Q_{\mathrm{ps}}}{Q_{\mathrm{s}} Q_{\mathrm{p}}}\right)+k T\left[\frac{\partial \ln \left(\frac{Q_{\mathrm{ps}}}{Q_{\mathrm{s}} Q_{\mathrm{p}}}\right)}{\partial T}\right]_{V, N_{\mathrm{s}}, N_{\mathrm{p}}}$

where $V$ is the total volume of polymer solution. It should be pointed out that the assumption of constant disorientation partition function might not be appropriate for extremely dilute solutions. Because the second term on the right-hand side of this expression is small compared to the first term, we have, by using Eqs. (4a) and (5) and assuming $v_{\mathrm{f}, \mathrm{s}}=v_{\mathrm{f}, \mathrm{s}}^{0}$ and $v_{\mathrm{f}, \mathrm{u}}=v_{\mathrm{f}, \mathrm{u}}^{0}$ for zero excess volume,

$$
\begin{aligned}
\Delta S_{\mathrm{mix}}= & -k\left[N_{\mathrm{s}} \ln \left(\frac{N_{\mathrm{s}} v_{\mathrm{f}, \mathrm{s}}^{0}}{N_{\mathrm{s}} v_{\mathrm{f}, \mathrm{s}}^{0}+N_{\mathrm{p}} \bar{z}_{\mathrm{p}} v_{\mathrm{f}, \mathrm{u}}^{0}}\right)\right. \\
& \left.+N_{\mathrm{p}} \ln \left(\frac{N_{\mathrm{p}} \bar{z}_{\mathrm{p}} v_{\mathrm{f}, \mathrm{u}}^{0}}{N_{\mathrm{s}} v_{\mathrm{f}, \mathrm{s}}^{0}+N_{\mathrm{p}} \bar{z}_{\mathrm{p}} v_{\mathrm{f}, \mathrm{u}}^{0}}\right)\right]
\end{aligned}
$$

where

$$
\bar{z}_{\mathrm{p}}=\frac{\sum_{i=1}^{N_{\mathrm{p}}} z_{\mathrm{p} i}}{N_{\mathrm{p}}}=\frac{\bar{M}_{\mathrm{n}} / \rho_{\mathrm{p}}}{M_{\mathrm{s}} / \rho_{\mathrm{s}}}
$$

fraction of solvent,

$$
\phi_{\mathrm{s}}=\frac{N_{\mathrm{s}}}{N_{\mathrm{s}}+N_{\mathrm{p}} \bar{z}_{\mathrm{p}}}
$$

Based on Eqs. (6b) and (6d), the molar entropy change for polymer solution is

$$
\begin{aligned}
\Delta \underline{S}_{\mathrm{mix}}= & -R\left\{x_{\mathrm{s}} \ln \left[\frac{\phi_{\mathrm{s}}}{\phi_{\mathrm{s}}+\left(1-\phi_{\mathrm{s}}\right) \alpha_{\mathrm{ps}}}\right]\right. \\
& \left.+\left(1-x_{\mathrm{s}}\right) \ln \left[\frac{\left(1-\phi_{\mathrm{s}}\right) \alpha_{\mathrm{ps}}}{\phi_{\mathrm{s}}+\left(1-\phi_{\mathrm{s}}\right) \alpha_{\mathrm{ps}}}\right]\right\}
\end{aligned}
$$

where $x_{\mathrm{s}}$ is the molar fraction of solvent, and

$\alpha_{\mathrm{ps}}=\frac{v_{\mathrm{f}, \mathrm{u}}^{0}}{v_{\mathrm{f}, \mathrm{s}}^{0}}=\frac{f_{\mathrm{p}}}{f_{\mathrm{s}}}$

$f_{\mathrm{s}}$ and $f_{\mathrm{p}}$ being, respectively, the free volume fractions of solvent and polymer. Eq. (7) is similar to that obtained by Hildebrand [25], except that the size distribution of polymer molecules was not considered in the latter. Other thermodynamic properties of the polymer solution can be derived in a similar way. It can be shown that, by neglecting the change of volume on mixing,

$$
\begin{aligned}
\Delta \underline{H}_{\text {mix }}= & \Delta \underline{E}_{\text {mix }}=R T \chi x_{\mathrm{s}}\left(1-\phi_{\mathrm{s}}\right) \\
= & R T \chi \frac{\phi_{\mathrm{s}}\left(1-\phi_{\mathrm{s}}\right) \bar{z}_{\mathrm{p}}}{1+\left(\bar{z}_{\mathrm{p}}-1\right) \phi_{\mathrm{s}}} \\
\Delta \underline{G}_{\mathrm{mix}}= & \Delta \underline{A}_{\text {mix }}=\Delta \underline{H}_{\mathrm{mix}}-T \Delta \underline{S}_{\mathrm{mix}} \\
= & R T\left\{\chi x_{\mathrm{s}}\left(1-\phi_{\mathrm{s}}\right)+x_{\mathrm{s}} \ln \left[\frac{\phi_{\mathrm{s}}}{\phi_{\mathrm{s}}+\left(1-\phi_{\mathrm{s}}\right) \alpha_{\mathrm{ps}}}\right]\right. \\
& \left.+\left(1-x_{\mathrm{s}}\right) \ln \left[\frac{\left(1-\phi_{\mathrm{s}}\right) \alpha_{\mathrm{ps}}}{\phi_{\mathrm{s}}+\left(1-\phi_{\mathrm{s}}\right) \alpha_{\mathrm{ps}}}\right]\right\}
\end{aligned}
$$

In these expressions, $\Delta \underline{H}_{\text {mix }}, \Delta \underline{E}_{\text {mix }}, \Delta \underline{G}_{\text {mix }}$ and $\Delta \underline{A}_{\text {mix }}$ are, respectively, the molar changes of enthalpy, internal energy, Gibbs free energy and Helmholtz free energy of polymer solution on mixing, and $\chi$ is defined in Eq. (1b). The chemical potential change of solvent in a polymer solution 
can be derived from the change of Gibbs free energy of mixing, $\Delta G_{\text {mix }}$, as

$$
\begin{aligned}
\mu_{\mathrm{s}}-\mu_{\mathrm{s}}^{0}= & N_{\mathrm{Av}}\left(\frac{\partial \Delta G_{\mathrm{mix}}}{\partial N_{\mathrm{s}}}\right)_{T, p, N_{\mathrm{p}}} \\
= & R T\left\{\ln \left[\frac{\phi_{\mathrm{s}}}{\phi_{\mathrm{s}}+\left(1-\phi_{\mathrm{s}}\right) \alpha_{\mathrm{ps}}}\right]\right. \\
& +\left(1-\frac{1}{\alpha_{\mathrm{ps}} \bar{z}_{\mathrm{p}}}\right) \frac{\left(1-\phi_{\mathrm{s}}\right) \alpha_{\mathrm{ps}}}{\phi_{\mathrm{s}}+\left(1-\phi_{\mathrm{s}}\right) \alpha_{\mathrm{ps}}} \\
& \left.+\chi\left(1-\phi_{\mathrm{s}}\right)^{2}\right\}=R T\left[\ln \phi_{\mathrm{s}}^{\prime}\right. \\
& \left.+\left(1-\frac{1}{\bar{z}_{\mathrm{p}}^{\prime}}\right)\left(1-\phi_{\mathrm{s}}^{\prime}\right)+\chi\left(1-\phi_{\mathrm{s}}\right)^{2}\right] \\
= & \Delta \bar{H}_{\mathrm{s}}-T \Delta \bar{S}_{\mathrm{s}}
\end{aligned}
$$

where in Eq. (10), $N_{\mathrm{Av}}$ is the Avogadro's number, $\phi_{\mathrm{s}}^{\prime}=$ $\phi_{\mathrm{s}} /\left[\phi_{\mathrm{s}}+\left(1-\phi_{\mathrm{s}}\right) \alpha_{\mathrm{ps}}\right]$, and $\bar{z}_{\mathrm{p}}^{\prime}=\alpha_{\mathrm{ps}} \bar{z}_{\mathrm{p}}$. The molar changes of enthalpy and entropy for solvent due to mixing, $\Delta \bar{H}_{\mathrm{s}}$ and $\Delta \bar{S}_{\mathrm{s}}$, can be expressed, respectively, as

$$
\Delta \bar{H}_{\mathrm{s}}=R T \chi\left(1-\phi_{\mathrm{s}}\right)^{2}
$$

and

$$
\Delta \bar{S}_{\mathrm{s}}=-R\left[\ln \phi_{\mathrm{s}}^{\prime}+\left(1-\frac{1}{\bar{z}_{\mathrm{p}}^{\prime}}\right)\left(1-\phi_{\mathrm{s}}^{\prime}\right)\right]
$$

Eq. (10) was used by Elbro et al. [24] to estimate the activity of solvent in a polymer solution; the entropy change in their expression was proposed by Hildebrand [25]. The result of Hildebrand was based on a probability consideration and, as pointed out previously, the size distribution of polymer molecules was not considered in his analysis, and therefore, the derivation was based on a constant molecule size. On the other hand, the present analysis is based on the size distribution of polymer molecules, that is, it is more mathematically rigorous and realistic than that of Hildebrand [25]. Note that the Flory-Huggins theory, Eq. (1), can be recovered as a special case of Eq. (10) by letting $\alpha_{\mathrm{ps}}=1$, and hence $\phi_{\mathrm{s}}^{\prime}=\phi_{\mathrm{s}}$ and $\bar{z}_{\mathrm{p}}^{\prime}=\bar{z}_{\mathrm{p}}$.

\section{Results and discussions}

For a solvent vapor, we have

$$
\mu_{\mathrm{s}}-\mu_{\mathrm{s}}^{0} \cong R T \ln \left(p_{\mathrm{s}} / p_{\mathrm{s}}^{0}\right)
$$

where $p_{\mathrm{s}}$ and $p_{\mathrm{s}}^{0}$ are, respectively, the vapor pressure of solvent for the case of a polymer solution and that for the case of pure solvent (Table 1). Eq. (11) is applicable as long as the deviation of the behavior of solvent vapor from that of ideal gas is insignificant. The applicability of the present
Table 1

Physical properties of toluene-polystyrene polymer solution at $25^{\circ} \mathrm{C}$

\begin{tabular}{lcl}
\hline & Toluene & Polystyrene \\
\hline$\rho_{\mathrm{s}}^{0}\left(\mathrm{~g} / \mathrm{cm}^{3}\right)$ & 1.063 & \\
$M_{\mathrm{s}}\left(\mathrm{g} / \mathrm{mole}^{2}\right)$ & 92.14 & \\
Density $\left(\mathrm{g} / \mathrm{cm}^{3}\right)$ & 0.862 & 1.083 \\
$\bar{M}_{\mathrm{n}}(\mathrm{g} / \mathrm{mole})$ & & 290,000 \\
$T_{\mathrm{g}}(\mathrm{K})$ & & 372.15 \\
\hline
\end{tabular}

model is justified by fitting it to two sets of experimental data reported in the literature. The first set of data is for a toluene-polystyrene polymer solution where the heat of mixing is negligible, which implies that $\chi \cong 0$. The experimental data and the results predicted by the present model are shown in Fig. 1. Here, the value of $\alpha_{\mathrm{ps}}$ is estimated based on Eqs. (10) and (11) through fitting the experimental data of solvent vapor pressure at various concentrations. The results based on Flory-Huggins theory, that is, $\alpha_{\mathrm{ps}}=1$, are also presented in Fig. 1 for comparison. Fig. 1 reveals that if the heat of mixing is negligible, appreciable improvement can be made by adopting the present model. The second set of data is for a benzenesilicone polymer solution where the heat of mixing is important. The experimental data for the heat of mixing are illustrated in Fig. 2, along with the results calculated from Eq. (8) (Table 2). The estimated values of $\chi$ for each silicone are listed in Table 3. The experimental data for the solvent vapor pressure are presented in Fig. 3, together with the results obtained from Eqs. (10) and (11), and from FloryHuggins theory. The estimated values of $\alpha_{\mathrm{ps}}$ are summarized in Table 3. Fig. 3 indicates that both the performance of the present model and that of Flory-Huggins theory are satisfactory for the case of benzene-silicone polymer solution. This is also reflected by that the estimated $\alpha_{\mathrm{ps}}$ shown in Table 3 is close to unity.

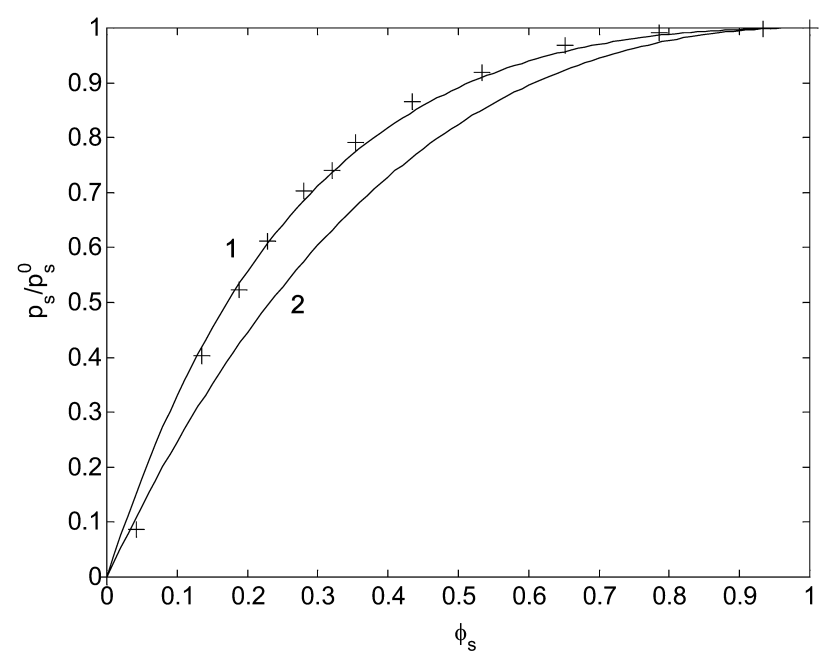

Fig. 1. Variation of $\left(p_{\mathrm{s}} / p_{\mathrm{s}}^{0}\right)$ as a function of $\phi_{\mathrm{s}}$ for toluene-polystyrene polymer solution at $25^{\circ} \mathrm{C}$. Discrete symbols, experimental data of Bawn et al. [19], curve 1, present result based on Eqs. (10) and (11), curve 2, result based on Flory-Huggins theory. 


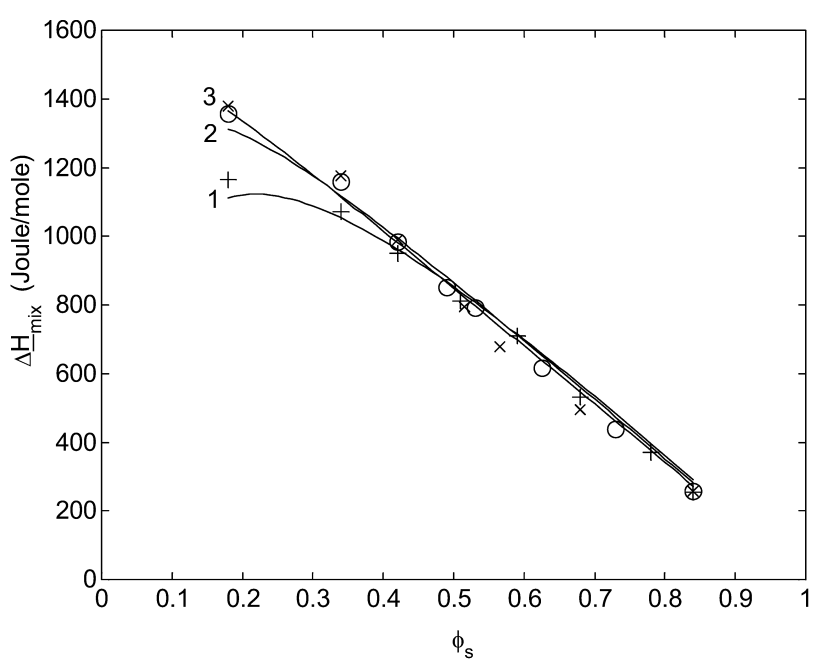

Fig. 2. Variation of $\Delta \underline{H}_{\text {mix }}$ as a function of $\phi_{\mathrm{s}}$ for benzene-silicone polymer solutions at $25^{\circ} \mathrm{C}$. Discrete symbols, experimental data of Newing [20], solid curves, present results based on Eq. (8). +, DC 50010 cstks.; o, DC 50050 cstks.; x, DC 200350 cstks.; curve 1, DC 50010 cstks.; 2, DC 500 50 cstks.; 3, DC 200350 cstks.

To judge if the estimated value of $\alpha_{\mathrm{ps}}$ is reasonable, the knowledge about the free volume contribution from both the solvent and the polymer need to be known. The free volume defined in Eqs. (4a) and (4b) is called the fluctuation free volume. For liquid phases, this quantity is much smaller than the empty free volume [30], which was adopted by Elbro et al. [24]. In general, the fluctuation free volume is close to the expansion free volume, which can be estimated by

$f_{\mathrm{s}}=1-\frac{\rho_{\mathrm{s}}}{\rho_{\mathrm{s}}^{0}}$

where $\rho_{\mathrm{s}}^{0}$ is the density of supercooled solvent at $0 \mathrm{~K}$. Because the fluctuation or expansion free volume of polymer is very limited in the literature, the free volume derived from a relaxation time analysis conducted by Williams et al. [31] is adopted. The free volume fraction of polymer beyond its glass temperature $T_{\mathrm{g}}$ can be estimated by

$f_{\mathrm{p}}=0.025+\alpha_{T_{\mathrm{g}}}\left(T-T_{\mathrm{g}}\right)$

where $\alpha_{T_{\mathrm{g}}}$ is the expansion coefficient of the free volume fraction of polymer. For polymer at a temperature below $T_{\mathrm{g}}$,

Table 2

Physical properties of benzene-silicone polymer solutions at $25^{\circ} \mathrm{C}$

\begin{tabular}{lcccc}
\hline & Benzene & $\begin{array}{l}\text { DC 500 } \\
10 \text { cstks. }\end{array}$ & $\begin{array}{l}\text { DC 500 } \\
50 \text { cstks. }\end{array}$ & $\begin{array}{l}\text { DC 200 } \\
350 \text { cstks. }\end{array}$ \\
\hline$\rho_{\mathrm{s}}^{0}\left(\mathrm{~g} / \mathrm{cm}^{3}\right)$ & 1.097 & & & \\
$M_{\mathrm{s}}\left(\mathrm{g} / \mathrm{mole}^{3}\right.$ & 78.11 & & & \\
Density $\left(\mathrm{g} / \mathrm{cm}^{3}\right)$ & 0.873 & 0.999 & 0.989 & 0.976 \\
$\bar{M}_{\mathrm{n}}(\mathrm{g} / \mathrm{mole})$ & & 1140 & 3850 & 15,700 \\
$T_{\mathrm{g}}(\mathrm{K})$ & 144.5 & 148 & 149.5 \\
$\alpha_{T_{\mathrm{g}}}\left(10^{-4} \mathrm{~K}^{-1}\right)$ & & 4.5 & 4.5 & 4.5 \\
\hline
\end{tabular}

Table 3

Estimated parameters for each polymer solution at $25^{\circ} \mathrm{C}$

\begin{tabular}{lllll}
\hline & & $\chi$ & $\alpha_{\mathrm{ps}}$ & \multicolumn{1}{c}{$\gamma_{\mathrm{c}}$} \\
\hline Toluene + polystyrene & & 0 & 0.685 & 5.179 \\
Benzene + silicones & DC 500 10 cstks. & 0.742 & 1.063 & 2.307 \\
& DC 500 50 cstks. & 0.713 & 0.902 & 1.991 \\
& DC 200 350 cstks. & 0.688 & 0.931 & 2.070 \\
\hline
\end{tabular}

since the free volume varies very slightly with the change in temperature, we assume that $f_{\mathrm{p}} \cong 0.025$ for $T<T_{\mathrm{g}}$. Therefore, a correction factor $\gamma_{\mathrm{c}}$, which can be used to judge if an estimated value of $\alpha_{\mathrm{ps}}$ is reasonable, can be defined as

$\gamma_{\mathrm{c}}=\frac{\alpha_{\mathrm{ps}}}{\left[0.025+\alpha_{T_{\mathrm{g}}}\left(T-T_{\mathrm{g}}\right)\right] /\left(1-\rho_{\mathrm{s}} / \rho_{\mathrm{s}}^{0}\right)}$

If Eqs. (12a) and (12b) are appropriate, then $\gamma_{\mathrm{c}}$ should close to unity. The huge size of polymer molecules implies that its mean free volume is much less than that of solvent, and, therefore, it is expected that $\alpha_{\mathrm{ps}}$ should be much smaller than unity. The values of $\alpha_{\mathrm{ps}}$ and $\gamma_{\mathrm{c}}$ shown in Table 3, however, are much larger than expected. One possible reason for this is that the change of the disorientation entropy of polymer molecules is ignored in the present analysis. When a polymer is diluted with a solvent, the obstacle for the orientating of polymer molecules is reduced considerably, and the disorientation entropy of polymer molecules increases considerably. Therefore, the total entropy change on mixing increases, and becomes larger than expected. Fig. 4 implies that the value of $\alpha_{\mathrm{ps}}$, and therefore $\gamma_{\mathrm{c}}$, estimated from $\Delta \underline{S}_{\text {mix }}$ will be overestimated. The value of $\alpha_{\mathrm{ps}}$ used by Elbro et al. [24] is on the order of 0.8 , which is also too large for many polymer solutions. Note that $\alpha_{\mathrm{ps}}$ is overestimated as unity in Flory-Huggins theory. Table 3 reveals that the change in the disorientation entropy on mixing for the polymer solutions examined is significant, which is ignored in previous studies.

\section{Conclusion}

In summary, the classic Flory-Huggins theory, which is based on an artificial lattice structure, for the chemical potential of a polymer solution is modified. We conclude that the effect of the disorientation entropy change of polymer molecules on mixing should be considered, or it needs to be combined with the effect of the free volumes of constituent solvent and polymer in a polymer solution, in the determination of its thermodynamic properties. We show that using the number-averaged size of polymer molecules to estimate the thermodynamic properties of a polymer solution is sufficient, knowing the exact size distribution is unnecessary. Through fitting available experimental data in the literature, we show that the performance of FloryHuggins theory can be improved considerably by adopting the present model. Also, it should be pointed out that, 

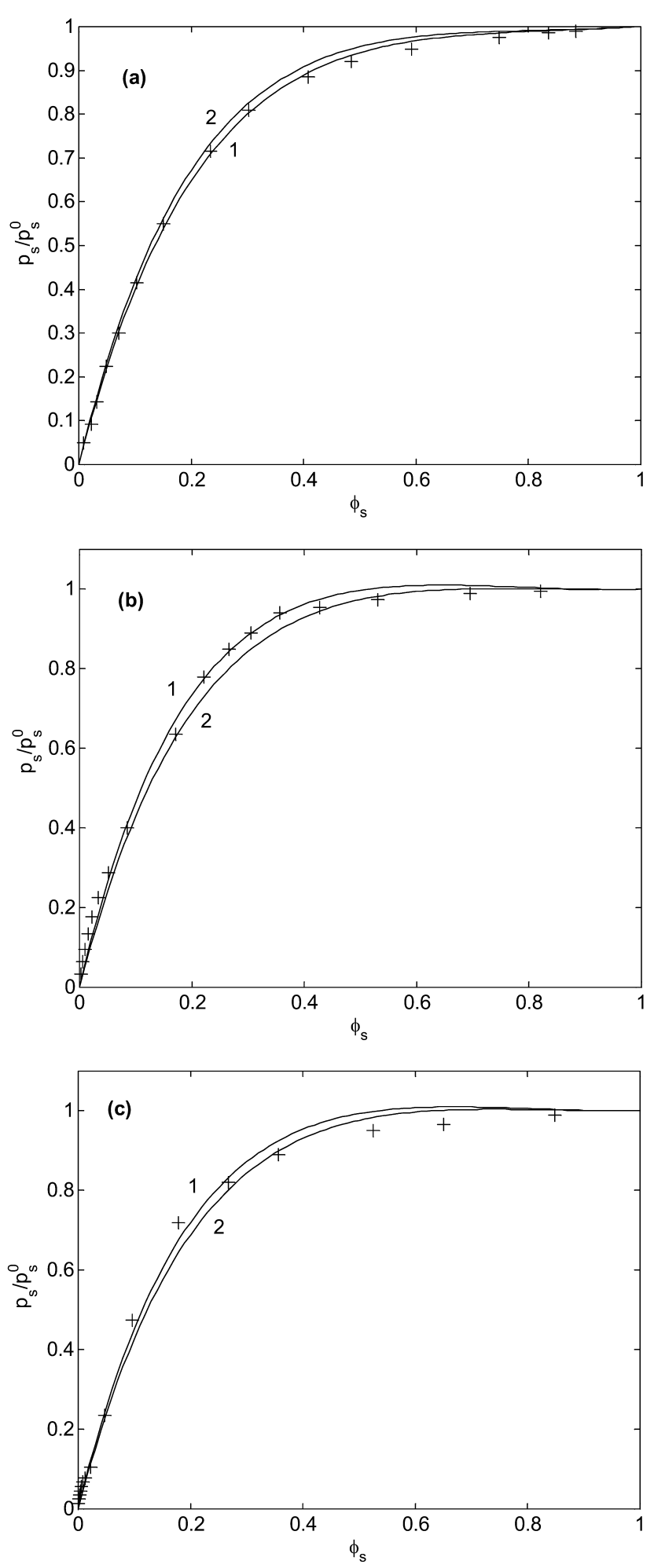

Fig. 3. (a) Variation of $\left(p_{\mathrm{s}} / p_{\mathrm{s}}^{0}\right)$ as a function of $\phi_{\mathrm{s}}$ for benzene-silicone DC 500 10 cstks. polymer solution at $25^{\circ} \mathrm{C}$. Discrete symbols, experimental data of Newing [20], curve 1, present result based on Eqs. (10) and (11), curve 2, result based on Flory-Huggins theory. (b) Variation of $\left(p_{\mathrm{s}} / p_{\mathrm{s}}^{0}\right)$ as a function of $\phi_{\mathrm{s}}$ for benzene-silicone DC 50050 cstks. polymer solution at $25^{\circ} \mathrm{C}$. Discrete symbols, experimental data of Newing [20], curve 1, present result based on Eqs. (10) and (11), curve 2, result based on Flory-Huggins theory. (c) Variation of $\left(p_{\mathrm{s}} / p_{\mathrm{s}}^{0}\right)$ as a function of $\phi_{\mathrm{s}}$ for benzene-silicone DC $200350 \mathrm{cstks}$. polymer solution at $25^{\circ} \mathrm{C}$. Discrete symbols, experimental data of Newing [20], curve 1, present result based on Eqs. (10) and (11), curve 2, result based on Flory-Huggins theory.

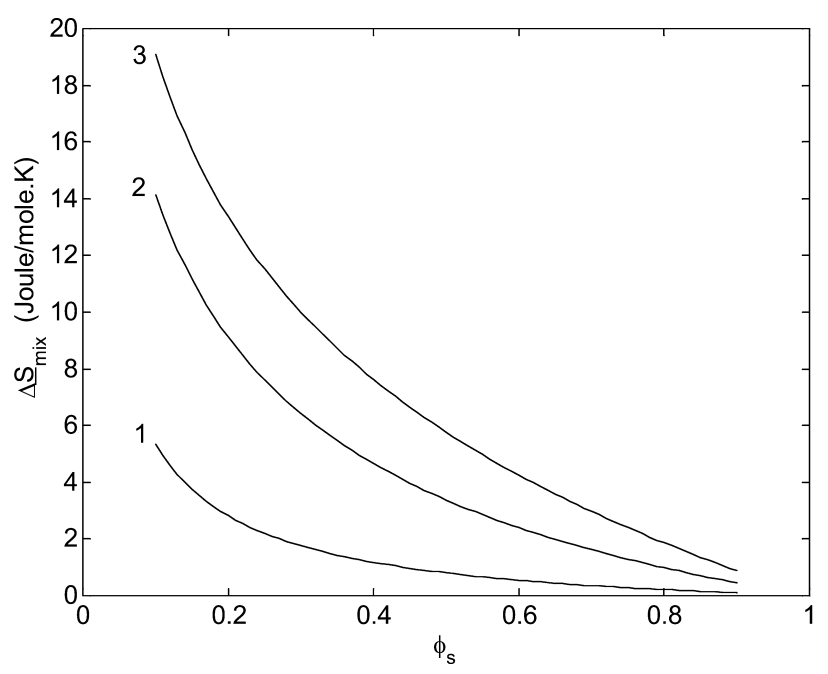

Fig. 4. Variation of $\Delta \underline{S}_{\text {mix }}$ calculated by Eq. 7 as a function $\phi_{\mathrm{s}}$ for toluenepolystyrene polymer solution for various $\alpha_{\mathrm{ps}}$ at $25^{\circ} \mathrm{C}$. Curve $1, \alpha_{\mathrm{ps}}=0.1$, $2, \alpha_{\mathrm{ps}}=0.5,3, \alpha_{\mathrm{ps}}=1.0$.

although the performance of the present model in predicting experimental data maybe comparable to that of other model, the former is theoretically sounder.

\section{Acknowledgements}

This work is supported by the National Science Council of the Republic of China.

\section{References}

[1] Batchelder T, Piatt J. Solid State Technol 1983;26:211.

[2] Ohara T, Matsumoto Y, Ohashi H. IEEE InterSociety Conference on Thermal Phenomena in Electronic Systems. Austin TX, Feb 5-8, 1992.

[3] Hsu JP, Lin SH, Chen WC, Tseng S. J Appl Phys 2001;89:1861.

[4] Chen WC, Chen JH, Yang SY, Cherng JY, Chang YH, Ho BC. J Appl Polym Sci 1996;60:1379.

[5] Tsai CC, Liu TJ, Chang YH, Tseng TW. Chem Eng Sci 1997;52:221.

[6] Liu BT, Chen WC, Hsu JP. Polymer 1999;40:1451.

[7] Ohtsuka Y, Koike Y. Appl Opt 1985;24:4316.

[8] Koike Y, Hidaka H, Ohtsuka Y. Appl Opt 1985;24:4321.

[9] Koike Y, Sumi Y, Ohtsuka Y. Appl Opt 1986;25:3356.

[10] Koike Y, Takezawa Y, Ohtsuka Y. Appl Opt 1988;27:486.

[11] Flory PJ. Principles of polymer chemistry. New York: Cornell University Press; 1967.

[12] Gee G, Orr WJC. Trans Faraday Soc 1946;42:507.

[13] Gee G. J Chem Soc 1947;280.

[14] Huggins ML. J Chem Phys 1941;9:440.

[15] Huggins ML. J Phys Chem 1942;46:151.

[16] Miller AR. Proc Camb Phil Soc 1942;38:109.

[17] Orr WJC. Trans Faraday Soc 1944;40:320.

[18] Guggenheim EA. Trans Faraday Soc 1948;44:1007.

[19] Bawn CE, Freeman RFJ, Kamaliddin AR. Trans Faraday Soc 1950; 46:677.

[20] Newing MJ. Trans Faraday Soc 1950;46:613.

[21] Patterson D. Macromolecules 1969;2:672.

[22] Oishi T, Prausnitz JM. Ind Eng Chem Process Des Dev 1978;17:333.

[23] Prausnitz JM, Lichtenthaler RN, de Azevedo EG. Molecular 
thermodynamics of fluid-phase equilibria. New Jersey: Prentice-Hall Inc; 1986.

[24] Elbro HS, Fredenslund AA, Rasmussen P. Macromolecules 1990;23: 4707.

[25] Hildebrand JH. J Chem Phys 1947;15:225.

[26] Hu Y, Zhou H, Liu H, Wu DT, Prausnitz JM. Fluid Phase Equilibria 1997;134:43.
[27] Chang BH, Bae YC. Polymer 2002;43:6627.

[28] Kirkwood JG. J Chem Phys 1950;18:380.

[29] Prigogine I. The molecular theory of solutions. New York: NorthHolland; 1957.

[30] Haward RN. J Macromol Sci-Revs Macromol Chem 1970;C4(2): 191.

[31] Williams ML, Landel RF, Ferry JD. J Am Chem Soc 1955;77:3701. 